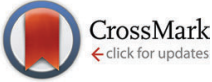

Cite this: Phys. Chem. Chem. Phys., 2016, 18, 4608

\title{
Shielding the chemical reactivity using graphene layers for controlling the surface properties of carbon materials $\dagger$
}

\begin{abstract}
A. E. Sedykh, E. G. Gordeev, E. O. Pentsak and V. P. Ananikov*
Graphene can efficiently shield chemical interactions and gradually decrease the binding to reactive defect areas. In the present study, we have used the observed graphene shielding effect to control the reactivity patterns on the carbon surface. The experimental findings show that a surface coating with a tiny carbon layer of 1-2 $\mathrm{nm}$ thickness is sufficient to shield the defect-mediated reactivity and create a surface with uniform binding ability. The shielding effect was directly observed using a combination of microscopy techniques and evaluated with computational modeling. The theoretical calculations indicate that a few graphene layers can drastically reduce the binding energy of the metal centers to the surface defects by $40-50 \mathrm{kcal} \mathrm{mol}^{-1}$. The construction of large carbon areas with controlled surface reactivity is extremely difficult, which is a key limitation in many practical applications. Indeed, the developed approach provides a flexible and simple tool to change the reactivity patterns on large surface areas within a few minutes.
\end{abstract}

Received 18th September 2015 Accepted 5th January 2016

DOI: $10.1039 / c 5 c p 05586 e$

www.rsc.org/pccp line defects, Stone-Wales defects, etc. $^{5}$ Carbon defects have been extensively investigated in the framework of developing efficient catalytic systems, ${ }^{6}$ sensors for gas molecules and biologically active compounds, ${ }^{7}$ nanoelectronic devices, ${ }^{8}$ and energy storage systems. ${ }^{9}$ Several outstanding applications of graphene-based materials in chemical technologies originated from the ability of graphene to undergo chemical and physical adsorption of atoms and molecules on the defect sites. The ability of graphene to establish covalent and van der Waals' interactions makes graphene an efficient adsorbent of aromatic compounds ${ }^{10}$ with possible application in purification systems to remove toxic impurities. Not surprisingly, the adsorption of gas molecules, ${ }^{11}$ organic compounds $^{10,12}$ and metal atoms ${ }^{13}$ on graphene and related carbon materials ${ }^{14}$ was the subject of many experimental and theoretical studies.

Recently, we reported an efficient approach for the imaging of reactive centers on the $2 \mathrm{D}$ carbon surface by adsorbing palladium nanoparticles: metal clusters that are formed from $\mathrm{Pd}_{2} \mathrm{dba}_{3}$ in a chloroform solution selectively attached to the defects of graphene layers and served as clearly visible markers. ${ }^{15}$ This methodology opened an excellent opportunity to make a molecular-level insight into the reactivity of the carbon surface. ${ }^{15}$

In the present study, we revealed the possibility of shielding the chemical reactivity of defect centers. The surface defects can be efficiently shielded by applying a coating with a thin layer of carbon. The reported experimental and theoretical studies in this article have shown that pristine graphene has 
strong shielding properties, and even a single carbon layer can noticeably mask the chemical reactivity.

\section{Results and discussion}

Using scanning electron microscopy, the boundaries of various types of surface defects can be easily observed on a graphite sample. Although the chemical reactivity of the defects cannot be directly characterized, it can be visualized using a notably sensitive procedure based on the attachment of palladium nanoparticles to the reactive sites. ${ }^{15}$ To map the chemical reactivity, we used $\mathrm{Pd}_{2} \mathrm{dba}_{3}$ as a contrast agent in the imaging procedure. Under mild conditions, palladium nanoparticles attach to the defect sites and serve as markers for the reactive centers of the carbon surface (see the Experimental part for details).
A typical carbon material with visible domains on the surface and palladium nanoparticles attached to them is shown in Fig. 1A. For a clear representation, we visualized the defect boundaries, which were observed using microscopy (green lines), and the attached palladium nanoparticles (red dots); the resulting map is shown in Fig. 1B. As observed in the nanoscale map, nanoparticles are preferentially located along the green lines. As expected, the surface defects are the areas of increased chemical reactivity, where the palladium nanoparticles were preferably bound.

Amazingly, we found another type of carbon material with clearly visible surface defects and domains, where the chemical reactivity of the defect centers was somehow shielded (Fig. 1C). A representative visualization of the defect boundaries and attached nanoparticles is shown in Fig. 1D. Although the domain boundaries are clearly present (green lines), the metal nanoparticles (red dots) are now uniformly distributed on the surface instead of locating along the defects. We became interested in this

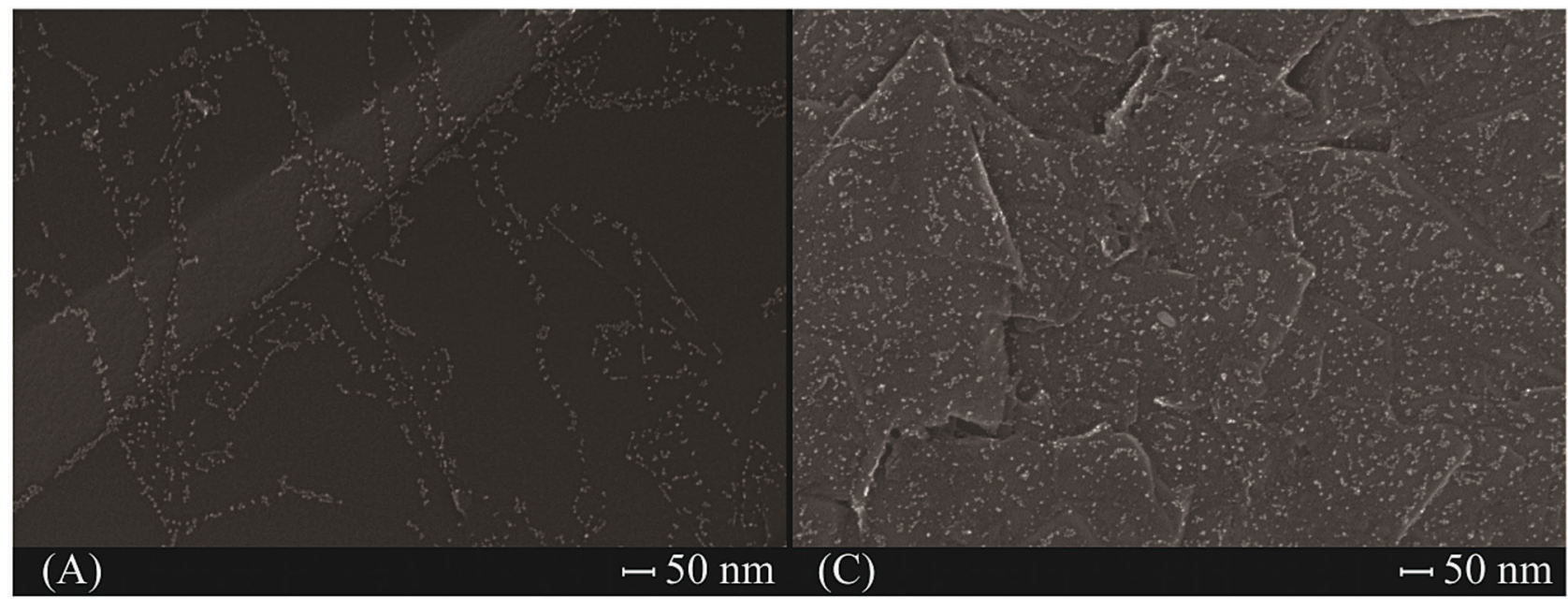

\section{$\downarrow \quad \begin{aligned} & \text { Visualisation of defect boundaries and } \\ & \text { palladium nanoparticles }\end{aligned}$}

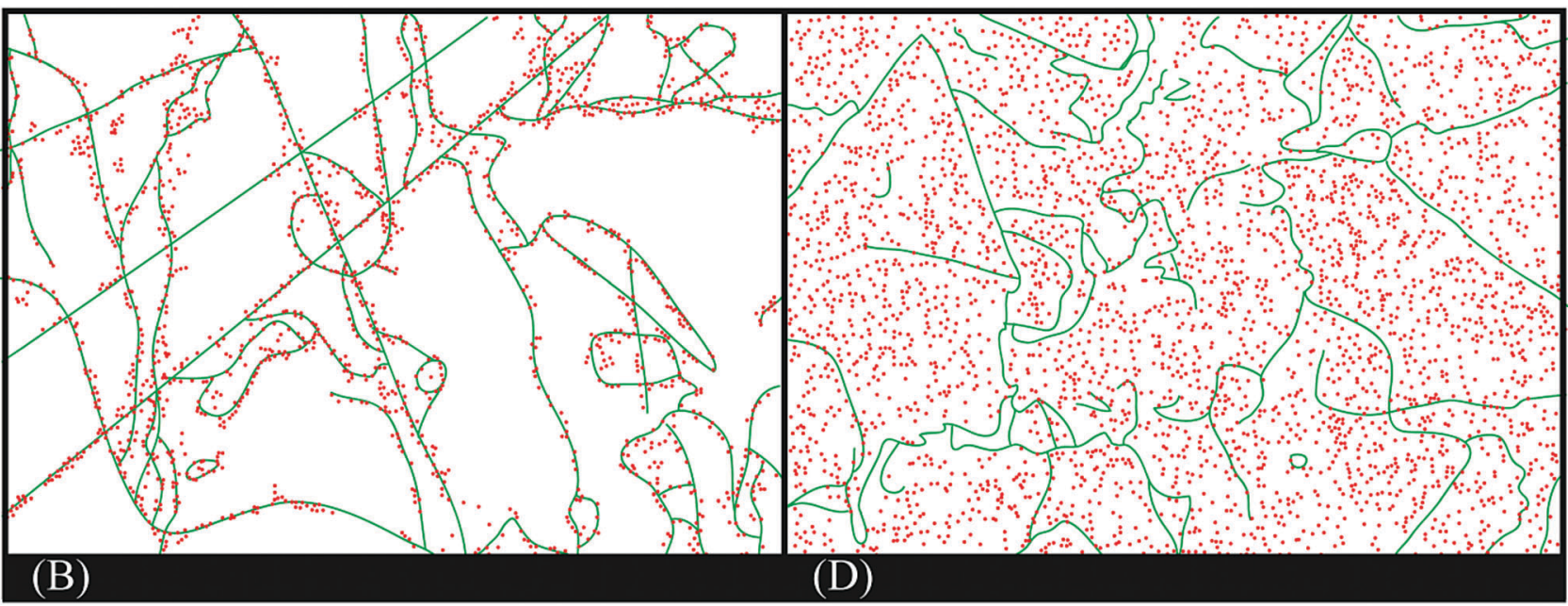

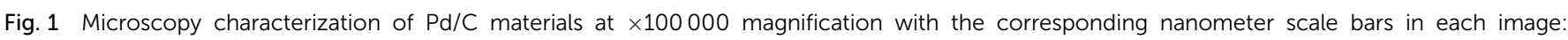

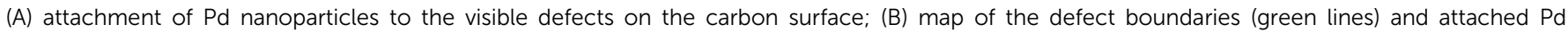

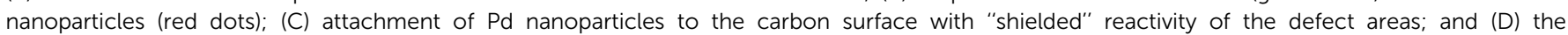
corresponding map of the defect boundaries (green lines) and attached Pd nanoparticles (red dots). 
significantly visible difference and studied these unusual areas in more details.

For detailed characterization, high-resolution scanning electron microscopy (SEM) and scanning transmission electron microscopy (STEM) images were recorded (Fig. 2). At low magnification, the SEM image showed the micrometer-sized graphite particle with a uniform distribution of palladium nanoparticles on the entire surface (Fig. 2A). In the bright-field scanning transmission electron microscopy (BF-STEM) image, the carbon layer boundaries are observed - the graphite particle is thicker where the image is darker (Fig. 2B). The annular dark-field scanning transmission electron microscopy (ADF-STEM) image has a better $\mathrm{S} / \mathrm{N}$ ratio and provides more information about the particles on both sides of the surface (Fig. 2C).

At higher magnifications, the palladium nanoparticles are observed with excellent resolution. Surprisingly, in this image, we found that the graphite surface was covered with a thin net-like material (Fig. 2D). The BF-STEM image reveals a uniform distribution of palladium nanoparticles (Fig. 2E).

In the ADF-STEM image, some additional nanoparticles are clearly visible (Fig. 2F); they are on the backside of this graphite particle and also uniformly distributed. The EDX analysis confirmed that this area contained only carbon and palladium (Fig. 2G). According to the EDX data, the net-like material on the graphite surface is carbon. It has become clear that this carbon on the graphite surface prevents the organization of palladium nanoparticles along the defect boundaries. A notably thin carbon coating appears to shield the chemical reactive sites.

We have also studied the next phase of the nanoparticles attachment after the defect boundaries were fully covered. For this purpose, the concentration of the palladium complex in solution was varied during nanoparticles deposition on the carbon surface. At higher concentrations of the metal precursor in solution (after attachment to the boundaries), it was found that palladium nanoparticles uniformly covered the graphite surface (Fig. S16, ESI $\dagger$ ).

To independently confirm that a thin carbon layer could shield the active sites on a graphite surface, we performed a theoretical computational modeling with quantum-chemical calculations. As a model of a graphene sheet, the molecules of coronene $\left(\mathrm{C}_{24} \mathrm{H}_{12}\right)$ and circum-coronene $\left(\mathrm{C}_{54} \mathrm{H}_{18}\right)$ were selected and studied at DFT and semi-empirical levels.

To reliably represent the stacked graphene system, the dispersion interactions were described according to Grimme's D3 corrections. ${ }^{16}$ Previously it has been shown that the DFT and semi-empirical levels used in the present study provide a reliable description of the graphene materials, which is consistent with experimental findings. ${ }^{17}$

First, we calculated the binding of the palladium marker to the defect site of the carbon material (Fig. 3A). Two types of carbon defects were studied: (1) missing carbon atom (i.e., one carbon atom was removed with $4+$ charge on the remaining part) and (2) organic cation $\mathrm{Ph}_{3} \mathrm{C}_{6}{ }^{\left({ }^{+}\right)}$, which was obtained by removing three hydride anions from 1,3,5-triphenylbenzene.

A Pd-L unit was used as a marker for the metal binding. With $\mathrm{L}=\mathrm{CO}$, useful information is provided by the $\mathrm{Pd}-\mathrm{L}_{\mathrm{C}}$ distance and $\mathrm{L}_{\mathrm{C}}$ charge. It has been shown that the PdCO model is notably sensitive to the changes in electron density at the palladium center. ${ }^{18}$ Next, we estimated the shielding of the reactive center by the graphene layers (Fig. 3B). In both cases (Fig. 3A and B), the binding energy was calculated according to the equation: $\Delta E=E$ (complex $)-E(\mathrm{PdCO})-E$ (carbon material).

The energy of the PdCO coordination with a pure "unshielded" defect was approximately $-100.0 \mathrm{kcal} \mathrm{mol} \mathrm{m}^{-1}$ (Table 1) at the semi-empirical and DFT levels. The value is consistent with the literature data. ${ }^{15,19}$ The direct binding of PdCO with the defect corresponds to the smallest Pd-C(sheet) interatomic distance. All atoms in the PdCO marker are positively charged according to Loewdin scheme (RI DFT), and the positive charges of the $\mathrm{Pd}, \mathrm{C}$ and $\mathrm{O}$ atoms are the largest at $n=0$ (Table 1). In accordance with the PM6-D3H4 Mulliken approach the oxygen atom is negatively charged. Both Loewdin and Mulliken approaches corresponded to each other with respect to the decrease in the total positive charge of the PdCO marker upon increasing the number of layers (see Table 1, Table S1, ESI $\dagger$ and Fig. 4).

It is interesting to note that an increase in the number of sheets in a stack leads to a gradual reduction in the positive charge of the defect-containing layer and an increase of positive charges on the central sheets of the stack (see Fig. S1, ESI $\dagger$ ). Simultaneously, the charge of the surface sheet that was connected with the PdCO marker decreased. This effect was more pronounced for the Loewdin charge distribution (Fig. S1, ESI $\dagger$ ). However, despite the charge transfer to the central sheets, the major part of the entire positive charge is localized on the outer sheets. This phenomenon may be used for designing nanoelectronic devices with multilayer graphene parts.

The insertion of the model graphene sheet between the defect and the PdCO molecule resulted in a considerably reduced complexation energy value (see values for $n=1$ in Table 1). For example, in the coronene complexes at the DFT levels, the insertion of the first additional coronene sheet decreased the complexation energy from -98.9 to $-58.7 \mathrm{kcal} \mathrm{mol}^{-1}$, i.e., the "shielding effect" of one coronene sheet was $40.2 \mathrm{kcal} \mathrm{mol}^{-1}$ (and $56.7 \mathrm{kcal} \mathrm{mol}^{-1}$ at the PM6-D3H4 level).

An increase in the number of sheets in the graphene stack leads to a gradual reduction in binding energy (see $\Delta E$ in Table 1 for the $\mathrm{C}_{54}$ system). In addition, a larger number of shielding layers $(n=1,2,3$; Fig. $3 \mathrm{~B})$ correspond to smaller positive charges of the $\mathrm{C}, \mathrm{O}$ and $\mathrm{Pd}$ atoms and the PdCO marker and a larger $\mathrm{Pd}-\mathrm{C}$ (sheet) interatomic distance (Table 1 and Fig. 4). For the $\mathrm{C}_{54}$ system the sum of the positive charges of the PdCO marker is decreased from $n=1$ (1.544) to $n=3$ (1.456). Such a charge variation may account for a shielding effect.

The $\mathrm{Pd}-\mathrm{C}_{(\mathrm{C}=\mathrm{O})}$ distance is sensitive to the insertion of the first graphene sheet and noticeably decreased after such insertion (this distance shortened to $0.14 \AA$ at the DFT level for the $\mathrm{C}_{24}$ system). Further increases in the number of sheets $(n=2$ and $n=3)$ did not change the $\mathrm{Pd}-\mathrm{C}_{(\mathrm{C}=\mathrm{O})}$ distance at the DFT and semi-empirical levels.

Changing the interlayer distance is also sensitive to the size of the system. For system $5(n=2)$, the interlayer distance was 

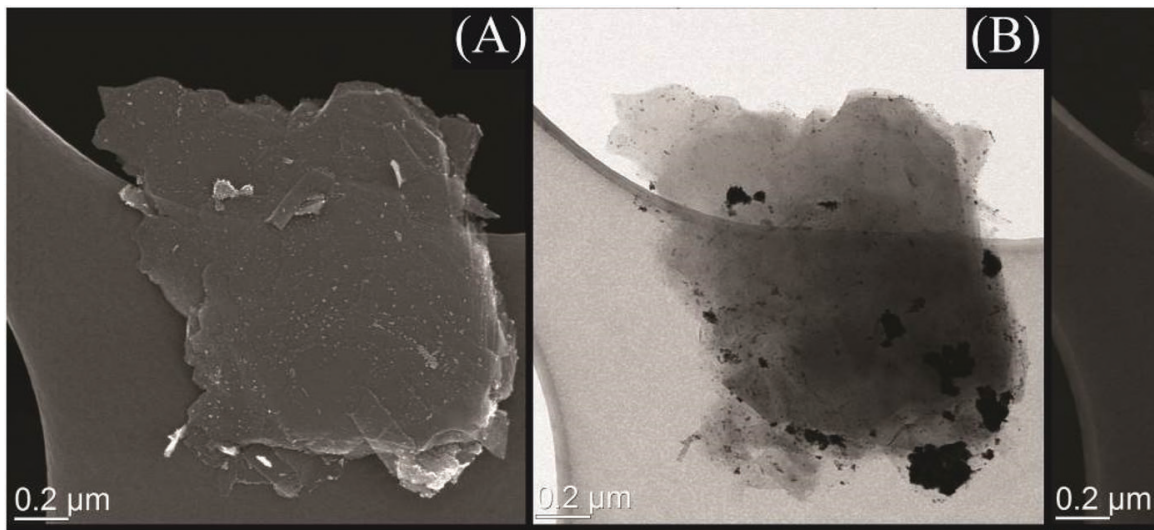

(C)
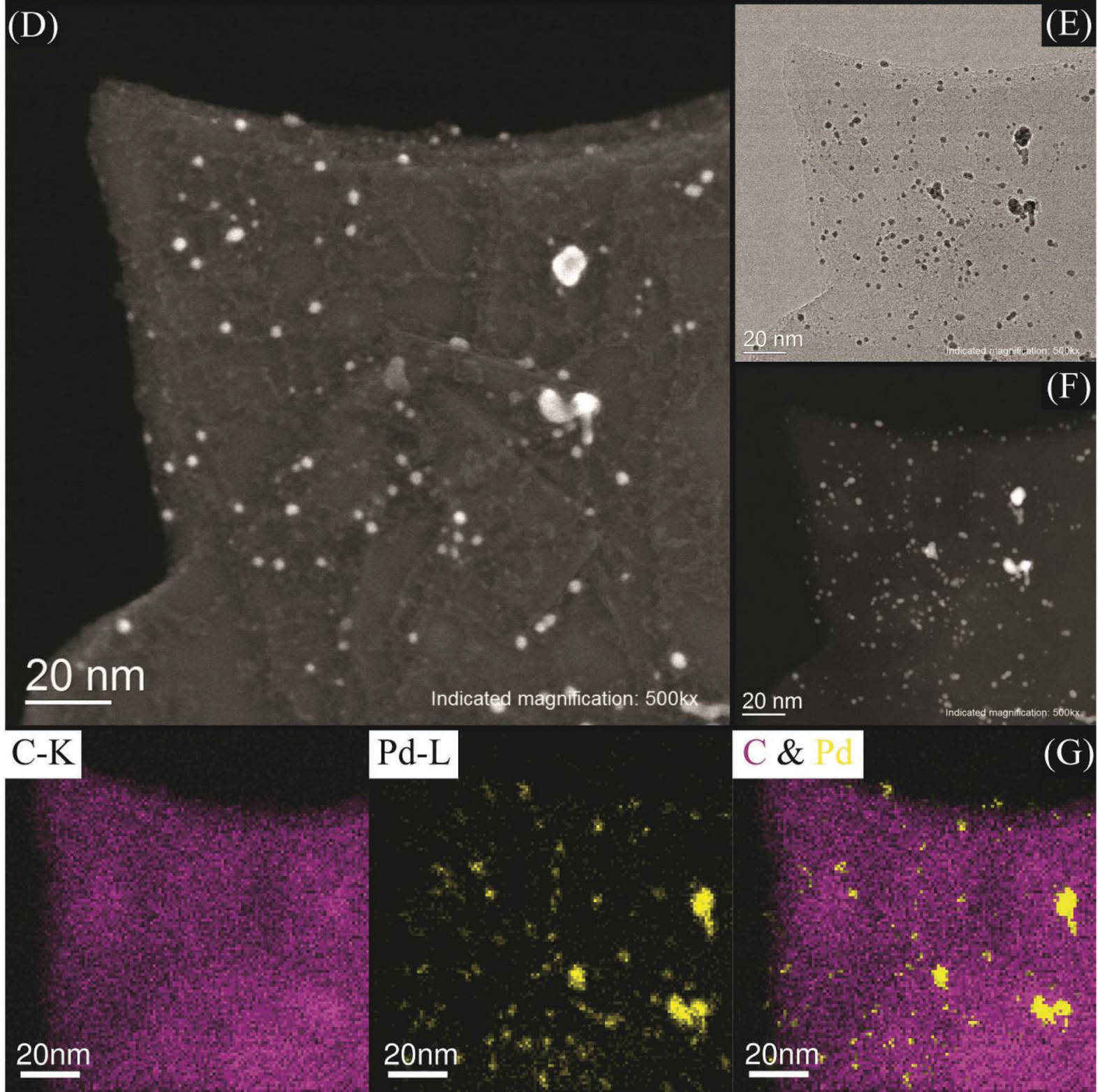

Fig. 2 Microscopy characterization of the Pd/C material at $\times 40000(A-C)$ and $\times 500000(D-G)$ magnifications with corresponding micrometer or nanometer scale bars in each image: (A) and (D) - SEM images; (B and E) - BF-STEM images; (C and F) - ADF-STEM images; and (G) - three EDX maps.

$3.43 \AA$ and its deviation from the equilibrium interlayer distance of "unperturbed" (without cation effect) bilayer system was $\Delta=0.05 \AA$ (Fig. 4). Adding a layer in system 7 resulted in a decrease of this change $(\Delta=0.04$ and 0.02$)$. Indeed, the 


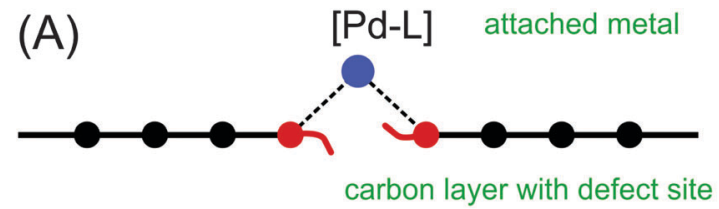

(B)

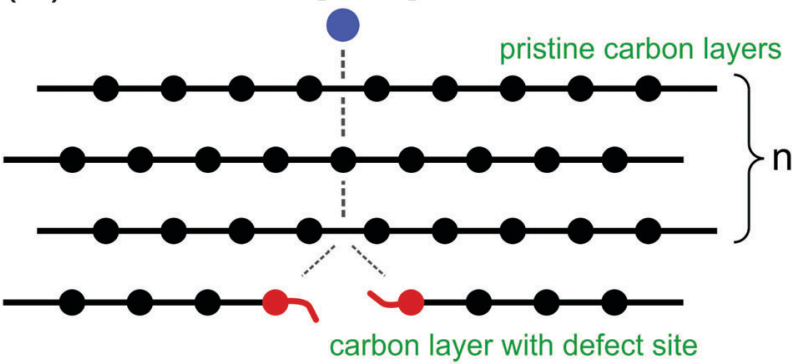

Fig. 3 Modelling of shielding by graphene layers: (A) - binding of the $[\mathrm{PdL}]$ to the defect site; $(\mathrm{B})$ - shielding of the $[\mathrm{PdL}]-$ defect by pristine graphene layers.

Table 1 Binding energies $\left(\Delta E, \mathrm{kcal} \mathrm{mol}^{-1}\right)$, atomic charges and interatomic distances for the coronene and circum-coronene model systems

\begin{tabular}{|c|c|c|c|c|c|}
\hline Number of carbon layers, $n$ & & 0 & 1 & 2 & 3 \\
\hline \multirow[t]{2}{*}{$\Delta E, \mathrm{kcal} \mathrm{mol}^{-1 a}$} & $\mathrm{C}_{54}$ & -107.4 & -50.7 & -46.0 & -44 \\
\hline & $\mathrm{C}_{24}$ & -98.9 & -58.7 & -50.1 & -60 \\
\hline $\mathrm{C}_{(\mathrm{C}=\mathrm{O})}$ charge $^{b}$ & $\mathrm{C}_{24}$ & +0.105 & +0.093 & +0.079 & +0.0 \\
\hline O charge & $\mathrm{C}_{24}$ & +0.252 & +0.177 & +0.153 & +0.1 \\
\hline Pd charge & $\mathrm{C}_{24}$ & +0.307 & +0.225 & +0.165 & +0.13 \\
\hline Total PdCO charge ${ }^{c}$ & $\mathrm{C}_{24}$ & +0.664 & +0.495 & +0.397 & +0.3 \\
\hline \multirow[t]{2}{*}{$\mathrm{Pd}-\mathrm{C}(\mathrm{C}=\mathrm{O})$ distance, $\AA$} & $\mathrm{C}_{54}$ & 2.004 & 1.956 & 1.959 & 1.959 \\
\hline & $\mathrm{C}_{24}$ & 2.097 & 1.957 & 1.957 & 1.957 \\
\hline \multirow[t]{2}{*}{ Pd-C(sheet) distance, $\AA^{d}$} & $\mathrm{C}_{54}$ & 2.081 & 2.106 & 2.118 & 2.113 \\
\hline & $\mathrm{C}_{24}$ & 1.971 & 2.127 & 2.127 & 2.127 \\
\hline
\end{tabular}

${ }^{a}$ For the $\mathrm{C}_{24}$ system, the RI PBE def2-SVP ZORA level was used; for the $\mathrm{C}_{54}$ system, the PM6-D3H4 level was used. ${ }^{b}$ The calculated values of Loewdin charges (for Mulliken charges see Table S1, ESI, and Fig. 4). For the coronene systems, geometry optimization was performed at the RI PBE level; for the circum-coronene systems, geometry optimization was performed at the PM6-D3H4 level. ${ }^{c}$ The sum of charges of the Pd, $\mathrm{C}$ and $\mathrm{O}$ atoms. ${ }^{d}$ The shortest $\mathrm{Pd}-\mathrm{C}($ sheet) interatomic distances.

observed shielding effect led to a dissipation of the influence of a defect site.

For both model systems, the most significant changes in binding energy, atomic charges and interatomic distances occurred after the insertion of the first shielding graphene layer. The insertion of the second and third layers resulted in a similar trend in the changes of the studied parameters but with a less pronounced difference.

An example of the molecular arrangement of the studied system is shown in Fig. 4. The direct binding of the PdCO marker to the defect layer caused the cation structure to distort and transform from the planar form to the convex form. The insertion of only one shielding graphene sheet between the cation and the PdCO particle eliminated the distortion, and the arrangement became planar.
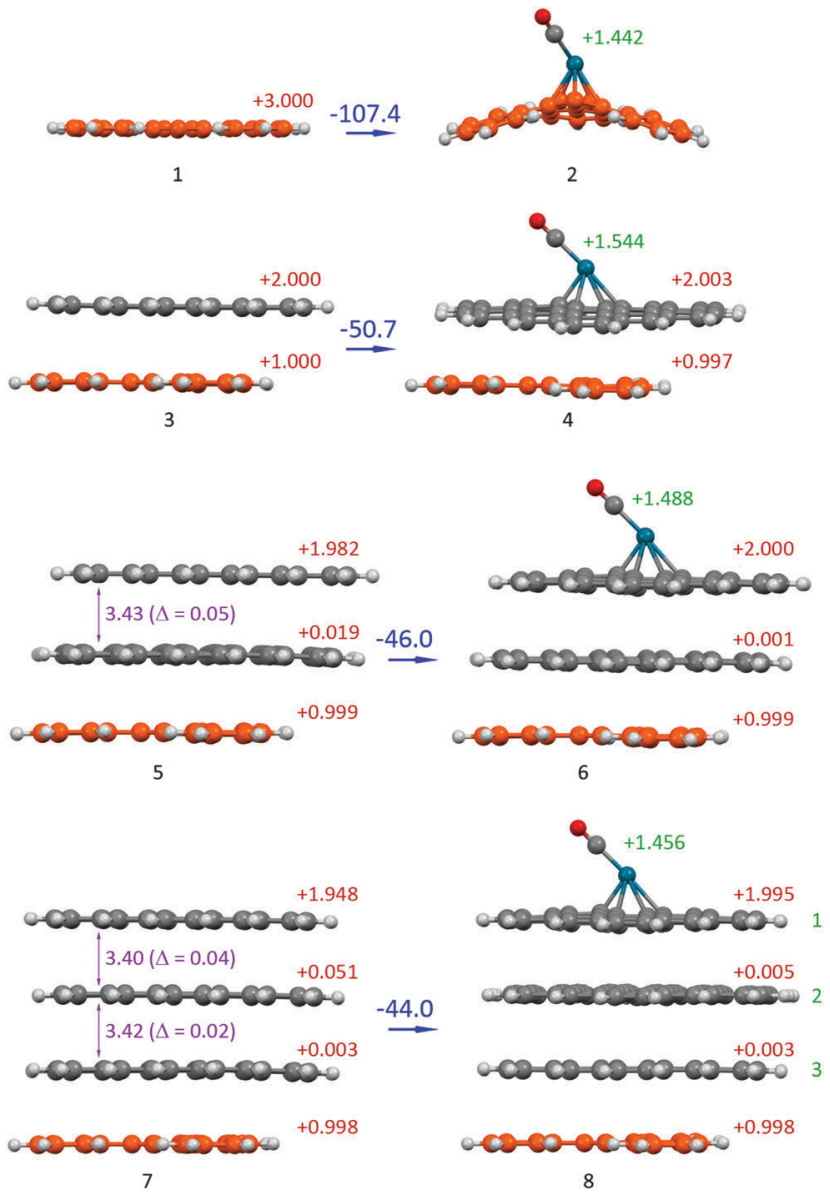

Fig. 4 Optimized molecular structures of the $\mathrm{Pd} / \mathrm{C}$ model system, which reflects the shielding effect of graphene layers: $n=0$ ( 1 and 2), $n=1$ ( 3 and 4$)$, $n=2$ (5 and 6) and $n=3$ (7 and 8) at the PM6-D3H4 level (see Fig. 3 for definition of $n$; the carbon defect layers are highlighted in orange; the total charge of the system is $3+)$. The binding energy $\left(\Delta E, \mathrm{kcal} \mathrm{mol}^{-1}\right)$ is shown in each case (blue values). The total Mulliken charges of each layer are denoted in red. The total Mulliken charges of the PdCO group are denoted in green.

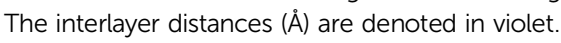

The theoretical calculations show the excellent shielding properties of graphene layers. Indeed, even a single layer can efficiently shield the chemical reactivity of the defect areas, which was observed in the experiment (Fig. 1).

These findings open an outstanding opportunity to control the surface reactivity of carbon materials and change the arrangement of metal nanoparticles on the carbon surface. To verify this possibility, we performed a dedicated experiment. A carbon material with reactive centers on the surface was coated with a carbon layer, which consisted of $\sim 95 \% \mathrm{sp}^{2}$ sites and formed from disordered graphitic islands of $15-20 \AA^{20}$ with subsequent attachment of palladium nanoparticles (Fig. 5). If our assumption is correct, the nanoparticle arrangement along the defect boundaries should disappear after a notably thin carbon layer is deposited.

The assumption was completely confirmed in the experiment. We observed a uniform distribution of palladium nanoparticles on the surface (Fig. 6B and D), which indicates the shielding of the originally presented defect boundaries (Fig. 5B). For comparison, 


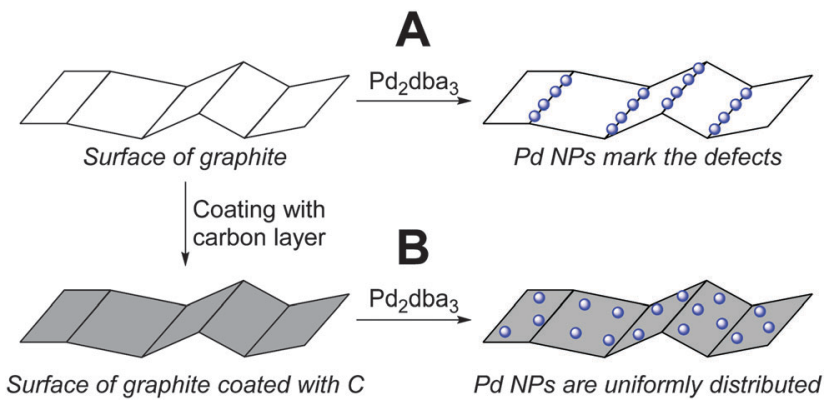

Fig. 5 (A) Pd nanoparticles localized on the defect areas (if uncoated carbon surface is used); (B) coating of the graphite surface by a thin carbon layer results in a uniform distribution of Pd nanoparticles.

the attachment of palladium nanoparticles to an unmodified sample led to an alignment along the defect boundaries (Fig. 6A and C), as we described for this approach (Fig. 5A).

Thus, the experimental findings have completely confirmed the idea. It should be emphasized that even a notably thin layer of carbon was sufficient to shield the chemical reactivity of the defects. Indeed, the theoretical calculations have shown that a single graphene layer can significantly reduce the susceptibility of nanoparticles to the defect centers. After coating with $1.4 \mathrm{~nm}$ of carbon, the defect boundaries remain clearly visible, whereas the preferential palladium binding to the defect areas disappeared (Fig. 6B and D). The images with higher magnification (Fig. 6C and D) show that the nanoparticles on the modified graphite are smaller ( $3.8 \pm 0.7 \mathrm{~nm}$, versus $5.8 \pm 0.9 \mathrm{~nm}$ on the clear graphite), which also confirms the change in the nature of the carbon support.

To confirm that coating only shielded the defects and did not create new active sites, BET (Brunauer-Emmett-Teller) specific surface area analysis was carried out. In these measurements, nitrogen gas was adsorbed on the material surface, particularly on the defects. The surface area of the unmodified graphite was measured as $4.127 \mathrm{~m}^{2} \mathrm{~g}^{-1}$. After coating the graphite with a carbon layer of $2.8 \mathrm{~nm}$ thickness, the measured BET response significantly decreased to $1.047 \mathrm{~m}^{2} \mathrm{~g}^{-1}$. Most likely, a thin coating on a nearly planar $2 \mathrm{D}$ surface cannot dramatically change the physical area of the sample; therefore, a change in the BET response indicates a decrease in the number of chemically reactive defect sites after coating.

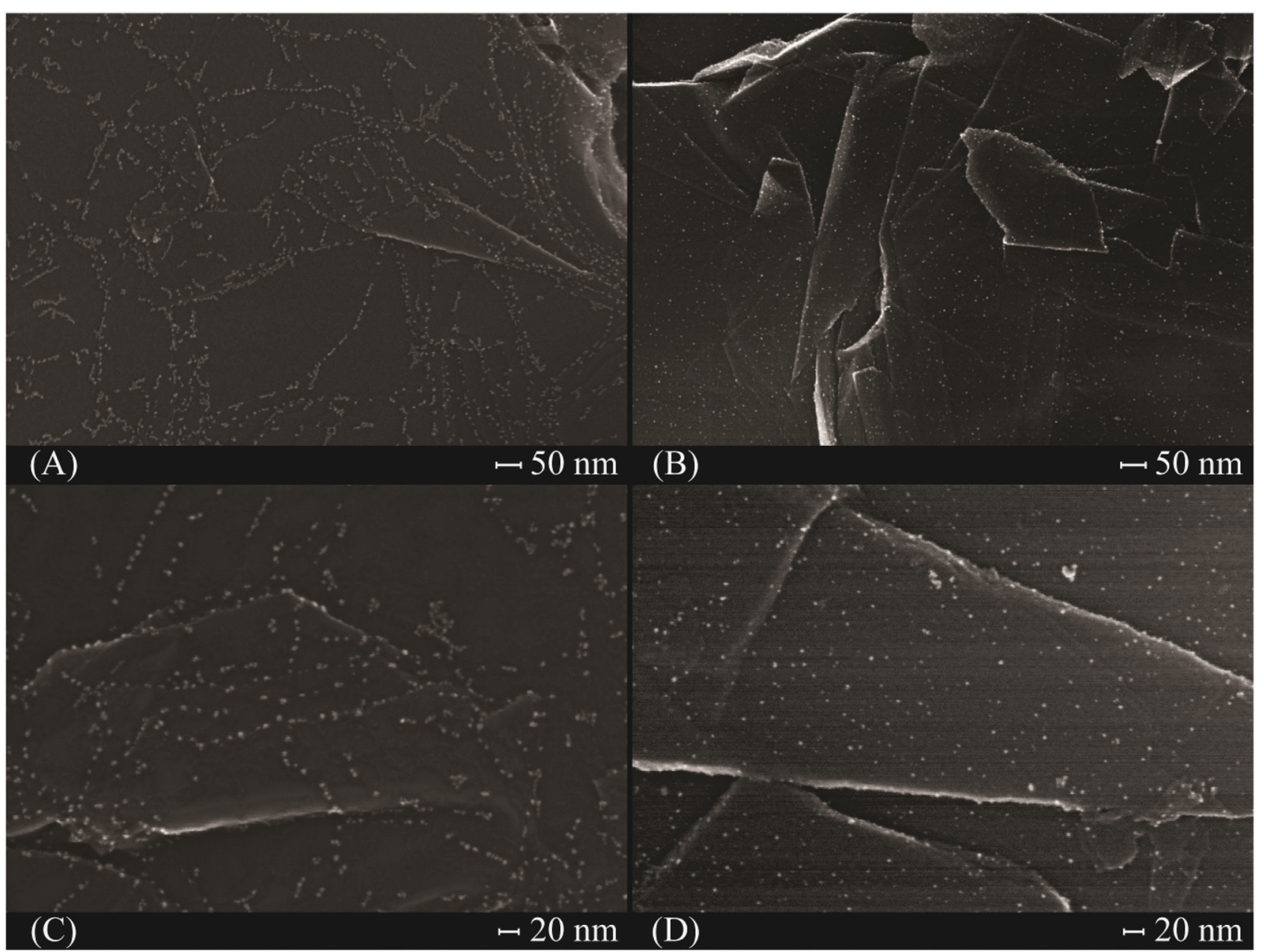

Fig. 6 FE-SEM images of Pd/C. (A and C) - Palladium nanoparticles on the graphite; (B and D) - palladium nanoparticles on the graphite that was coated with $1.4 \mathrm{~nm}$ of carbon. Microscopy characterization of the precipitates at $\times 100000$ (A and B) and $\times 200000$ (C and D) magnifications with corresponding nanometer scale bars in each image. 


\section{Conclusions}

To summarize, a fundamental difference in the binding of palladium nanoparticles to surface defects was established using electron microscopy (FE-SEM, BF-STEM, and ADF-STEM), theoretical calculations (DFT and PM6-D3H4) and BET surface area analysis. As expected, the specific binding of palladium nanoparticles to the defect areas was observed on regular carbon surfaces. However, on the carbon surface that was covered with a thin carbon layer ( 1-2 $\mathrm{nm})$, a uniform distribution of the deposited palladium nanoparticles was found. The theoretical calculations have shown that even a single graphene layer significantly reduces the binding energy of metal nanoparticles to the chemically reactive defect sites (by $\sim 40 \mathrm{kcal} \mathrm{mol}^{-1}$ ).

Thus, coating by a single pristine graphene layer or a few layers provides an excellent opportunity to shield the chemical reactivity. A notably sensitive test based on the attachment of metal nanoparticles has clearly shown the loss of reactivity of the visible defect areas on the carbon surface. The deposition of thin carbon layers is a simple and technically feasible procedure, which creates a flexible tool to control the reactivity of carbon materials and their interaction with other molecules. The proposed experimental technique is an efficient method to regulate the activity of graphite defects and design new nanostructured hybrid carbon materials. Using this carbon coating approach, one can switch the chemical-reactivity pattern of a carbon surface from defect-oriented specific binding to a uniform binding across the carbon surface.

\section{Experimental}

\section{General methods and materials}

$\mathrm{Pd}_{2} \mathrm{dba}_{3} \cdot \mathrm{CHCl}_{3}$ was synthesized according to the reported procedure. ${ }^{21}$ Unless otherwise noted, the experiments were performed in screw-cap glass tubes, which were equipped with a magnetic stir bar. Graphite powder of high purity $(90 \% \mathrm{w} / \mathrm{w}$ of particles with a size of less than $90 \mu \mathrm{m}$ ) was purchased from a commercial source.

The electron microscopy images were recorded using a Hitachi SU8000 field-emission scanning electron microscope (FE-SEM). For the FE-SEM measurements, the samples were fixed with a conductive silver paint on a $25 \mathrm{~mm}$ aluminum specimen stub. The images were acquired in a secondary electron mode at an accelerating voltage of $30 \mathrm{kV}$ and a working distance of 8-10 mm.

The high-resolution electron microscopy images were recorded using a Hitachi HD-2700 scanning transmission electron microscope (STEM), which was equipped with a CEOS $\mathrm{GmbH}$ spherical aberration (Cs) corrector. All the images were recorded at an accelerating voltage of $200 \mathrm{kV}$. The analysis time for the EDX-elemental mapping was 30 minutes.

The BET measurements were performed on the specific surface analyzer Catacon Sorbtometer-M and obtained from multipoint BET calculations.

\section{Coating of graphite with carbon}

Graphite powder (average $60 \mathrm{mg}$ ) was placed in a Petri dish (inner diameter: $88 \mathrm{~mm}$ ) and uniformly distributed on the glass to create a nearly monolayer. A Petri dish with the carbon material was carefully placed into the Cressington Carbon Coater 208c. At a pressure of $1.5 \times 10^{-4} \mathrm{mbar}$, the sample was coated with a layer of carbon. The thickness was measured in situ using the Cressington Thickness Monitor MTM-10.

\section{Deposition of Pd on carbon materials}

The procedure was performed as previously reported. ${ }^{15} \operatorname{Pd}_{2} \mathrm{dba}_{3}$. $\mathrm{CHCl}_{3}(1.2 \mathrm{mg}, 1.16 \mu \mathrm{mol})$ was dissolved in $\mathrm{CHCl}_{3}(2.4 \mathrm{~mL})$. Parts of this solution were added to the carbon materials to obtain $0.5 \%$ $\mathrm{Pd} / \mathrm{C}$ material. To the unmodified graphite $(12.2 \mathrm{mg}), 0.61 \mathrm{~mL}$ of a complex solution (containing $0.305 \mathrm{mg}$ of $\mathrm{Pd}_{2} \mathrm{dba}_{3} \cdot \mathrm{CHCl}_{3}$ ) was added. To coated with carbon graphite $(11.1 \mathrm{mg}), 0.56 \mathrm{~mL}$ of a complex solution (containing $0.280 \mathrm{mg}$ of $\mathrm{Pd}_{2} \mathrm{dba}_{3} \cdot \mathrm{CHCl}_{3}$ ) was added. The complex was decomposed at $50{ }^{\circ} \mathrm{C}$ for $2 \mathrm{~h}$. After the completion of the reaction, the solutions became colorless. The value was consistent with the literature data. The carbon powders were washed with acetone and $\mathrm{CHCl}_{3}$ and subsequently dried.

\section{Computational procedures}

For all RI PBE ${ }^{22}$ calculations, the def2-SVP ZORA ${ }^{23}$ basis set and def2-SVP/J auxiliary basis set were used (Orca 3.0.3 ${ }^{24}$ program package). The RI (resolution of identity) approximation allows in particular to speed up the DFT calculations using pure (nonhybrid) functionals.

The ZORA (zeroth-order regular approximation) is applied for the description of the relativistic effects in DFT methods. Relativistic effects may be important for molecular systems containing atoms of heavy elements such as palladium. ${ }^{25}$

The $\mathrm{D} 3 \mathrm{BJ}^{16}$ dispersion correction was applied to more accurately describe the dispersion interactions between graphene sheets within RI DFT calculations.

The MOPAC 2012 program package ${ }^{26}$ was used for the semiempirical PM6-D3H4 ${ }^{27}$ calculations with parameter GNORM =0.2.

The visualization of optimized molecular structures was performed by using the Mercury 3.5.1 program package. ${ }^{28}$

\section{Acknowledgements}

The project was supported by the Russian Science Foundation (RSF Grant 14-13-01030). The authors thank Hitachi HighTechnologies (Japan) and Interlab LLC (Russia) for providing access to the advanced microscopy hardware. The authors acknowledge Kurnakov Institute of General and Inorganic Chemistry, Moscow, for the BET analysis.

\section{Notes and references}

1 A. K. Geim and K. S. Novoselov, Nat. Mater., 2007, 6, 183.

2 (a) Y. Chen, C. Tan, H. Zhang and L. Wang, Chem. Soc. Rev., 2015, 44, 2681; (b) C. Chung, Y. K. Kim, D. Shin, S. R. Ryoo, B. H. Hong and D. H. Min, Acc. Chem. Res., 2013, 46, 2211; (c) A. Jankovic, S. Erakovic, M. Vukasinovic-Sekulic, V. Miskovic-Stankovic, S. J. Park and K. Y. Rhee, Prog. Org. Coat., 2015, 83, 1; (d) X. Hu and Q. Zhou, Chem. Rev., 2013, 
113, 3815; (e) A. E. Jakus, E. B. Secor, A. L. Rutz, S. W. Jordan, M. C. Hersam and R. N. Shah, ACS Nano, 2015, 9, 4636; $(f)$ D. Nuvoli, V. Alzari, R. Sanna, S. Scognamillo, J. Alongi, G. Malucelli and A. Mariani, J. Nanopart. Res., 2013, 15, 1512; (g) C. M. Santos, J. Mangadlao, F. Ahmed, A. Leon, R. C. Advincula and D. F. Rodrigues, Nanotechnology, 2012, 23, 395101; $(h)$ H. Shen, L. Zhang, M. Liu and Z. Zhang, Theranostics, 2012, 2, 283; ( $i$ ) J. K. Wang, G. M. Xiong, M. Zhu, B. Özyilmaz, A. H. Castro Neto, N. S. Tan and C. Choong, ACS Appl. Mater. Interfaces, 2015, 7, 8275; $(j)$ Z. Wang, H. Zeng and L. Sun, J. Mater. Chem. C, 2015, 3, 1157; (k) K. Yang, L. Feng, H. Hong, W. Cai and Z. Liu, Nat. Protoc., 2013, 8, 2392; (l) Y. Yang, A. M. Asiri, Z. Tang, D. Du and Y. Lin, Biochem. Pharmacol., 2013, 16, 365; $(m)$ P. T. Yin, S. Shah, M. Chhowalla and K.-B. Lee, Chem. Rev., 2015, 115, 2483.

3 (a) D. Bitounis, H. Ali-Boucetta, B. H. Hong, D. H. Min and K. Kostarelos, Adv. Mater., 2013, 25, 2258; (b) X. Hu and Q. Zhou, Chem. Rev., 2013, 113, 3815; (c) H. Y. Mao, S. Laurent, W. Chen, O. Akhavan, M. Imani, A. A. Ashkarran and M. Mahmoudi, Chem. Rev., 2013, 113, 3407; (d) S. Shi, F. Chen, E. B. Ehlerding and W. Cai, Bioconjugate Chem., 2014, 25, 1609; (e) Y. Zhang, T. R. Nayak, H. Hong and W. Cai, Nanoscale, 2012, 4, 3833.

4 (a) L. H. Hess, A. Lyuleeva, B. M. Blaschke, M. Sachsenhauser, M. Seifert, J. A. Garrido and F. Deubel, ACS Appl. Mater. Interfaces, 2014, 6, 9705; (b) L. Kong, A. Enders, T. S. Rahman and P. A. Dowben, J. Phys.: Condens. Matter, 2014, 26, 443001; (c) C. X. Lim, H. Y. Hoh, P. K. Ang and K. P. Loh, Anal. Chem., 2010, 82, 7387; (d) H. Wang, X. Bo and L. Guo, Sens. Actuators, B, 2014, 192, 181; (e) Y. Yue, G. Hu, M. Zheng, Y. Guo, J. Cao and S. Shao, Carbon, 2012, 50, 107.

5 (a) F. Banhart, J. Kotakoski and A. V. Krasheninnikov, ACS Nano, 2011, 5, 26; (b) D. W. Boukhvalov and M. I. Katsnelson, Nano Lett., 2008, 8, 4374; (c) L. Cao, M. J. Meziani, S. Sahu and Y.-P. Sun, Acc. Chem. Res., 2013, 46, 171; (d) O. Cretu, A. V. Krasheninnikov, J. A. Rodríguez-Manzo, L. Sun, R. M. Nieminen and F. Banhart, Phys. Rev. Lett., 2010, 105, 1; (e) M. F. De Lange, T. J. H. Vlugt, J. Gascon and F. Kapteijn, Microporous Mesoporous Mater., 2014, 200, 199; $(f)$ X. Jia, J. Campos-Delgado, M. Terrones, V. Meunier and M. S. Dresselhaus, Nanoscale, 2011, 3, 86; ( $g$ ) A. Mesaros, S. Papanikolaou, C. F. J. Flipse, D. Sadri and J. Zaanen, Phys. Rev. B: Condens. Matter Mater. Phys., 2010, 82, 1; (h) J. Moellmer, E. B. Celer, R. Luebke, A. J. Cairns, R. Staudt, M. Eddaoudi and M. Thommes, Microporous Mesoporous Mater., 2010, 129, 345; (i) M. A. Pimenta, G. Dresselhaus, M. S. Dresselhaus, L. G. Cançado, A. Jorio and R. Saito, Phys. Chem. Chem. Phys., 2007, 9, 1276; (j) D. Wei and J. Kivioja, Nanoscale, 2013, 5, 10108; (k) S. C. Xu, S. Irle, D. G. Musaev and M. C. Lin, J. Phys. Chem. B, 2006, 110, 21135; ( $l$ ) S. C. Xu, S. Irle, D. G. Musaev and M. C. Lin, J. Phys. Chem. C, 2009, 113, 18772; (m) S. C. Xu, S. Irle, D. G. Musaev and M. C. Lin, J. Phys. Chem. C, 2007, 111, 1355.

6 (a) B. Dai, K. Chen, Y. Wang, L. Kang and M. Zhu, ACS Catal., 2015, 5, 2541; (b) C. Huang, C. Li and G. Shi, Energy Environ. Sci., 2012, 5, 8848; (c) S. D. Kushch, N. S. Kujunko and B. P. Tarasov, Russ. J. Gen. Chem., 2009, 79, 706; (d) Z. Lin, M. Song, Y. Ding, Y. Liu, M. Liu and C. Wong,
Phys. Chem. Chem. Phys., 2012, 14, 3381; (e) B. F. Machado and P. Serp, Catal. Sci. Technol., 2012, 2, 54; $(f)$ L. Wang, A. Ambrosi and M. Pumera, Angew. Chem., Int. Ed., 2013, 52, 13818; $(g)$ R. Wang, Z. Wu, C. Chen, Z. Qin, H. Zhu, G. Wang, H. Wang, C. Wu, W. Dong, W. Fan and J. Wang, Chem. Commun., 2013, 49, 8250; (h) T. Xue, S. Jiang, Y. Qu, Q. Su, R. Cheng, S. Dubin, C. Y. Chiu, R. Kaner, Y. Huang and X. Duan, Angew. Chem., Int. Ed., 2012, 51, 3822; (i) Y. Yao, Z. Yang, D. Zhang, W. Peng, H. Sun and S. Wang, Ind. Eng. Chem. Res., 2012, 51, 6044; $(j)$ T. Zeng, X. Zhang, Y. Ma, H. Niu and Y. Cai, J. Mater. Chem., 2012, 22, 18658; ( $k$ ) M. Zhou, A. Zhang, Z. Dai, C. Zhang and Y. P. Feng, J. Chem. Phys., 2010, 132, 1.

7 (a) A. Ambrosi, C. K. Chua, A. Bonanni and M. Pumera, Chem. Rev., 2014, 114, 7150; (b) R. Bogue, Assem. Autom., 2008, 28, 211; (c) M. Carbone, L. Gorton and R. Antiochia, Electroanalysis, 2015, 16; (d) J. Chang, G. Zhou, E. R. Christensen, R. Heideman and J. Chen, Anal. Bioanal. Chem., 2014, 406, 3957; (e) X. Deng, H. Tang and J. Jiang, Anal. Bioanal. Chem., 2014, 406, 6903; $(f)$ J. D. Fowler, M. J. Allen, V. C. Tung, Y. Yang, R. B. Kaner and B. H. Weiller, ACS Nano, 2009, 3, 301; $(g)$ T. Gan and S. Hu, Microchim. Acta, 2011, 175, 1; (h) Q. He, S. Wu, Z. Yin and H. Zhang, Chem. Sci., 2012, 3, 1764; (i) Y. Liu, X. Dong and P. Chen, Chem. Soc. Rev., 2012, 41, 2283; (j) F. Schedin, A. K. Geim, S. V Morozov, E. W. Hill, P. Blake, M. I. Katsnelson and K. S. Novoselov, Nat. Mater., 2007, 6, 652; (k) Y. Shao, J. Wang, H. Wu, J. Liu, I. A. Aksay and Y. Lin, Electroanalysis, 2010, 22, 1027.

8 (a) M. Freitag, Nat. Nanotechnol., 2008, 3, 455; (b) S. Ghosh, I. Calizo, D. Teweldebrhan, E. P. Pokatilov, D. L. Nika, A. A. Balandin, W. Bao, F. Miao and C. N. Lau, Appl. Phys. Lett., 2008, 92, 1; (c) G. Iannaccone, G. Fiori, M. MacUcci, P. Michetti, M. Cheli, A. Betti and P. Marconcini, Tech. Dig. Int. Electron Devices Meet., 2009, 245; (d) E. A. Il'ichev, A. E. Kuleshov, R. M. Nabiev, G. N. Petrukhin, G. S. Rychkov, O. A. Sakharov and E. S. Chernyavskaya, Tech. Phys. Lett., 2013, 39, 808; (e) R. S. Sundaram, M. Steiner, H. Y. Chiu, M. Engel, A. a. Bol, R. Krupke, M. Burghard, K. Kern and P. Avouris, Nano Lett., 2011, 11, 3833; ( $f$ ) X. Zheng, M. Zhang, X. Shi, G. Wang, L. Zheng, Y. Yu, A. Huang, P. K. Chu, H. Gao, W. Ren, Z. Di and X. Wang, Adv. Funct. Mater., 2015, 25, 1805.

9 (a) L. Dai, Acc. Chem. Res., 2013, 46, 31; (b) B. Dawoud, E. Amer and D. Gross, Int. J. Energy Res., 2007, 31, 135; (c) H. Gwon, H.-S. Kim, K. U. Lee, D.-H. Seo, Y. C. Park, Y.-S. Lee, B. T. Ahn and K. Kang, Energy Environ. Sci., 2011, 4, 1277; (d) J. Hou, Y. Shao, M. W. Ellis, R. B. Moore and B. Yi, Phys. Chem. Chem. Phys., 2011, 13, 15384; (e) F. Liu and D. Xue, Mater. Res. Innovations, 2015, 19, 7; $(f)$ P. Martin, Chem. Rec., 2009, 9, 211; (g) M. Pumera, Energy Environ. Sci., 2011, 4, 668; (h) J. Zhu, D. Yang, Z. Yin, Q. Yan and H. Zhang, Small, 2014, 10, 1.

10 (a) J. Björk, F. Hanke, C. A. Palma, P. Samori, M. Cecchini and M. Persson, J. Phys. Chem. Lett., 2010, 1, 3407; (b) S. D. Chakarova-Käck, A. Vojvodic, J. Kleis, P. Hyldgaard and 
E. Schröder, New J. Phys., 2010, 12, 013017; (c) M. Corno, A. Rimola, V. Bolis and P. Ugliengo, Phys. Chem. Chem. Phys., 2010, 12, 6309; (d) Y. J. Dappe, M. Andersen, R. Balog, L. Hornekær and X. Bouju, Phys. Rev. B: Condens. Matter Mater. Phys., 2015, 91, 1; (e) L. M. Woods, Ş. C. Bǎdescu and T. L. Reinecke, Phys. Rev. B: Condens. Matter Mater. Phys., 2007, 75, 1; $(f)$ R. Zacharia, H. Ulbricht and T. Hertel, Phys. Rev. B: Condens. Matter Mater. Phys., 2004, 69, 1; (g) X. Zhang, H. Ji, X. Zhang, Z. Wang and D. Xiao, Anal. Methods, 2015, 7, 3229; (h) J. Zhao, J. P. Lu, J. Han and C. K. Yang, Appl. Phys. Lett., 2003, 82, 3746.

11 (a) D. W. Boukhvalov, Surf. Sci., 2010, 604, 2190; (b) H. Chang, J. Do Lee, S. M. Lee and Y. H. Lee, Appl. Phys. Lett., 2001, 79, 3863; (c) O. Leenaerts, B. Partoens and F. M. Peeters, Appl. Phys. Lett., 2008, 92, 243125; (d) O. Leenaerts, B. Partoens and F. M. Peeters, Phys. Rev. B, 2008, 77, 125416; (e) J. Ma, A. Michaelides, D. Alfè, L. Schimka, G. Kresse and E. Wang, Phys. Rev. B: Condens. Matter Mater. Phys., 2011, 84, 1; $(f)$ Y. Miura, H. Kasai, W. Diño, H. Nakanishi and T. Sugimoto, J. Appl. Phys., 2003, 93, 3395; ( $g$ ) S. Peng and K. J. Cho, Nano Lett., 2003, 3, 513; (h) A. Sadrzadeh, A. A. Farajian and B. I. Yakobson, Appl. Phys. Lett., 2008, 92, 12; (i) A. Saffarzadeh, J. Appl. Phys., 2010, 107, 114309; $(j)$ S. Santucci, S. Picozzi, F. Di Gregorio, L. Lozzi, C. Cantalini, L. Valentini, J. M. Kenny and B. Delley, J. Chem. Phys., 2003, 119, 10904; (k) Y. Sun, L. Chen, F. Zhang, D. Li, H. Pan and J. Ye, Solid State Commun., 2010, 150, 1906; (l) C. Thierfelder, M. Witte, S. Blankenburg, E. Rauls and W. G. Schmidt, Surf. Sci., 2011, 605, 746; $(m)$ T. O. Wehling, A. I. Lichtenstein and M. I. Katsnelson, Appl. Phys. Lett., 2008, 93, 1; (n) J. Zhao, A. Buldum, J. Han and J. P. Lu, Nanotechnology, 2002, 13, 195.

12 T. Pankewitz and W. Klopper, J. Phys. Chem. C, 2007, 111, 18917.

13 (a) K. T. Chan, J. B. Neaton and M. L. Cohen, Phys. Rev. B: Condens. Matter Mater. Phys., 2008, 77, 1; (b) X. Fan, W. T. Zheng and J. L. Kuo, ACS Appl. Mater. Interfaces, 2012, 4, 2432; (c) J. Granatier, P. Lazar, M. Otyepka and P. Hobza, J. Chem. Theory Comput., 2011, 7, 3743; (d) J. Grantier, P. Lazar, R. Prucek, K. Šafářová and R. Zbořil, J. Phys. Chem. C, 2012, 116, 14151; (e) S. M. Kozlov, F. Viñes and A. Görling, J. Phys. Chem. C, 2012, 116, 7360; $(f)$ A. Smolyanitsky and V. K. Tewary, J. Phys.: Condens. Matter, 2011, 23, 355006; (g) Z. Xu and M. J. Buehler, J. Phys.: Condens. Matter, 2010, 22, 485301.
14 (a) A. V. Zabula, A. S. Filatov, S. N. Spisak, A. Yu. Rogachev and M. A. Petrukhina, Science, 2011, 333, 1008; (b) A. V. Zabula, S. N. Spisak, A. S. Filatov and M. A. Petrukhina, Angew. Chem., Int. Ed., 2012, 51, 12194; (c) A. S. Filatov, A. V. Zabula, S. N. Spisak, A. Yu. Rogachev and M. A. Petrukhina, Angew. Chem., Int. Ed., 2014, 53, 140; (d) A. S. Filatov, S. N. Spisak, A. V. Zabula, J. McNeely, A. Yu. Rogachev and M. A. Petrukhina, Chem. Sci., 2015, 6, 1959.

15 E. O. Pentsak, A. S. Kashin, M. V. Polynski, K. O. Kvashnina, P. Glatzel and V. P. Ananikov, Chem. Sci., 2015, 6, 3302.

16 (a) S. Grimme, J. Antony, S. Ehrlich and H. Krieg, J. Chem. Phys., 2010, 132, 154104; (b) C. Steffen, K. Thomas, U. Huniar, A. Hellweg, O. Rubner and A. Schroer, J. Comput. Chem., 2010, 31, 2967.

17 (a) M. A. Vincent and I. H. Hillier, J. Chem. Inf. Model., 2014, 54, 2255; (b) E. G. Gordeev, M. V Polynski and V. P. Ananikov, Phys. Chem. Chem. Phys., 2013, 15, 18815.

18 (a) A. Dedieu, Chem. Rev., 2000, 100, 543; (b) M. Filatov, Chem. Phys. Lett., 2003, 373, 131.

19 (a) M. V. Polynski and V. P. Ananikov, Computational Modeling of Graphene Systems Containing Transition Metal Atoms and Clusters, Understanding Organometallic Reaction Mechanisms and Catalysis, Wiley-VCH, Weinheim, 2014; (b) Y. Tang, Z. Yang and X. Dai, J. Chem. Phys., 2011, 135, 224704; (c) X. Liu, L. Li, C. Meng and Y. Han, J. Phys. Chem. C, 2012, 116, 2710.

20 J. Robertson and E. O'Reilly, Phys. Rev. B: Condens. Matter Mater. Phys., 1987, 35, 2946.

21 S. S. Zalesskiy and V. P. Ananikov, Organometallics, 2012, 31, 2302.

22 J. P. Perdew, K. Burke and M. Ernzerhof, Phys. Rev. Lett., 1996, 77, 3865.

23 D. A. Pantazis, X. Y. Chen, C. R. Landis and F. Neese, J. Chem. Theory Comput., 2008, 4, 908.

24 F. Neese, The ORCA program system, Wiley Interdiscip. Rev.: Comput. Mol. Sci., 2012, 2, 73.

25 G. Eickerling, R. Mastalerz, V. Herz, W. Scherer, H.-J. Himmel and M. Reiher, J. Chem. Theory Comput., 2007, 3, 2182.

26 J. J. P. Stewart, Stewart Computational Chemistry, MOPAC2012, Version 15.156L, HTTP://OpenMOPAC.net.

27 (a) P. Hobza, Acc. Chem. Res., 2012, 45, 663; (b) J. J. P. Stewart, J. Mol. Model., 2007, 13, 1173.

28 Mercury 3.5.1 (Build RC5), CCDC 2001-2014, http://www. ccdc.cam.ac.uk/mercury/. 